\title{
Jagged Love: Narratives of Romance on Dating Apps during COVID-19
}

\author{
Lisa Portolan ${ }^{1}$ (D . Jodi McAlister ${ }^{2}$
}

Accepted: 5 July 2021 / Published online: 20 July 2021

(C) The Author(s), under exclusive licence to Springer Science+Business Media, LLC, part of Springer Nature 2021

\begin{abstract}
The romance plot is one of the most pervasive narratives in Western society. It is a cultural masterplot: a story with which almost everyone is familiar, which can deeply and intrinsically shape the way we think about how we live. This article examines how people interact with the romance masterplot and how it affects their search for love on dating apps in Australia during the global pandemic in 2020. Using data drawn from interviews and focus groups, and combining sociological research and narrative theory, we explore the way the romance masterplot affects the way people approach romance in dating apps, and how this has been complicated by the pandemic. We propose that participants use of dating apps in this period was characterised by 'jagged love', which we have theorised in relation to Zygmunt Bauman's notion of 'liquid love'. This manifested cyclically, as participants turned to the apps seeking the security offered by the romance masterplot in a time of global uncertainty; swiped, matched, and messaged in large numbers, and lost faith in the apps ability to deliver on the romantic masterplot. While episodic behaviour on dating apps is not new, the pandemic heightened and accelerated the process as people desperately sought the certainty offered by the romance masterplot, quickly lost faith because of the limitations of the pandemic, and then returned again.
\end{abstract}

Keywords Dating apps $\cdot$ Romance narratives $\cdot$ Covid-19 $\cdot$ Intimacy $\cdot$ Romantic love $\cdot$ Jagged love

Lisa Portolan

19626260@student.westernsydney.edu.au

Jodi McAlister

jodi.mcalister@deakin.edu.au

1 Institute for Culture and Society, Western Sydney University, Parramatta, Australia

2 School of Communication and Creative Arts, Deakin University, Melbourne, Australia 


\section{Introduction}

Narrative theorist H. Porter Abbott (2008, p. 46) describes masterplots as 'stories that we tell over and over in myriad forms and that connect vitally with our deepest values, wishes, and fears'. These are stories with which almost everyone is familiar, which can deeply and intrinsically shape the way we think about how we live. They are thus 'a kind of cultural glue that holds societies together '(Abbott, 2008, p. 47), or what Frank Kermode (1979, p. 113) calls 'the mythological structure of a society from which we derive comfort, and which it may be uncomfortable to dispute'. Importantly, '[m]asterplots are more than just stories we know... They are operations by which we interpret reality; they are "mental maps" onto which we try to fit the reality we see outside ourselves even if it does not fit very well' (Roche et al., 2018, p. 36).

One of the most obvious examples of a masterplot in contemporary Western culture is the romance plot. This is a plot into which many people inscribe themselves, and it has become one of the primary ways in which people narrativize their lives. Romance plots are visible in the vast majority of the media we consume, and have become 'culturally sanctioned templates for interpreting reality around us' (Roche et al., 2018, p. 36). The plot has clear milestones and events: you meet someone, you fall in love, you marry, you have children, you live happily ever after. These milestones are flexible and might shift in terms of significance and order-for instance, not all couples marry, have children, or wait until after marriage to have children-but the cultural primacy of the romance plot, and our almost universal familiarity with it, cannot be denied.

In this article, we examine the ways in which people interact with the romance masterplot and how it affects the way they think about and approach the search for a romantic partner. We draw together sociological research and narrative theory in order to explore this in a specific context: on dating apps in Australia, in a period with a major complicating factor in the global COVID-19 pandemic. Using data drawn from interviews and focus groups, we discuss major themes and trends, examining the ways in which the romantic masterplot affects the way people approach romance in dating apps, how they measure themselves against it and imagine themselves as potential romantic protagonists, and how this has been complicated by the pandemic.

We contend that participants' use of dating apps in this period were characterised by a phenomenon we have termed 'jagged love'. This manifested cyclically, as participants turned to dating apps desperately seeking the security offered by the romantic masterplot; swiped, matched, and sent direct messages (DMs) in large numbers; became ambivalent and/or lost faith in the apps as a means by which they could embody the masterplot; deleted the apps; experienced loneliness; and returned quickly to the apps to repeat the cycle. While this pattern was not necessarily markedly different to the ways in which people used dating apps in the past, it was heightened and accelerated by the pandemic, as people desperately sought the certainty offered by the romantic masterplot. This caused what had hitherto been a relatively fluid cycle to become fragmented and frenetic: or, as we have put it, jagged. 


\section{Background}

\section{Dating Apps}

In this research, we use the term 'dating app' broadly. This is a complicated terrain, and not all apps are designed for the same purpose. Some are clear that their intended use is to find a long-term romantic partner, while the architecture of others is designed to facilitate short-term connections and hook-ups rather than romance. However, people do not always use the apps in a way aligned with that app's stated purpose, and may maintain different profiles on the same app seeking different things (ie. a relationship profile and a hook-up profile). The data collected for this article focuses on users of Tinder and/or Bumble, but many of the participants also maintained profiles on other apps as well, demonstrating the complexity and porousness of this space.

Across the past two decades, dating apps have become a central point of discussion in relation to dating, relationships and intimacy. Many Australian singles (and non-singles) frequently use an app or multiple apps to navigate and negotiate relationships (Bailey, 2012). Independent research indicates that rates of dating app usage have seen significant growth in Australia across the last decade (YouGov, 2017). A survey of 2000 people conducted by Nielsen in 2010 revealed that 25 percent of Australians had tried dating apps (Bailey, 2012). In 2015 Tinder announced that 15 percent of the Australian population had joined the app (Bruce-Smith, 2017). Most recently, a 2017 study conducted by YouGov indicated 52 percent of Australian singles had used a dating app to make a romantic connection. The same study indicated, usage was particularly high for single Australians between 25 and 34, with 60 percent having used a dating app to make a romantic connection.

Opinions relating to dating app usage in contemporary media have varied; however, an overarching narrative has emerged, in which dating apps have colonised love, created a virtual emotional marketplace, fostered a hook-up culture and devalued traditional institutions such as marriage, monogamy and long-term partnerships (Fetters \& Tiffany, 2020). Other negative commentary has centred around health and concern over physical and emotional safety (Ng, 2019), as well as a perceived rise in Sexually Transmitted Diseases (STDs) as a result of an appfacilitated hook-up culture (AFP, 2019). For older generations who may never have used dating apps (or are suddenly required to take a foray into this space), censure of the dating app landscape is high (Gebel, 2019); while for younger generations (particularly those within an 18-28 year old bracket), dating apps present as a pre-condition to romance, an integral part of the dating experience. This younger generation has never dated within an IRL (In Real Life) environment, and many would prefer not to (Fetters, 2018).

In the 2020s, it is hard to imagine a world without dating apps or digitally facilitated relationships. Looking back, computer-based match-making technology had its naissance in the 1960s, but its genealogy can be traced to personal ads in the seventeenth century (Macleod \& McArthur, 2018). Brainz (2011) cites the 
first online dating site as kiss.com, which was registered in 1994, and the midnineties saw a rise in similar match-making website like match.com, RSVP.com and e-harmony. The growth of relationship websites-and, subsequently, mobile dating apps-has been steady across the last twenty years. The last decade saw a panoply of dating apps mushroom, catering towards a diversity of groups and people. The shift to mobile dating app usage significantly changed the dynamic, its affordances making online dating ubiquitous. Users can now access matches from any location, and can also locate matches in situ (for example, by opening Tinder in a bar, users are able to see which singles are closest to them, based on the geo-spatial functionalities).

Leading the dating app charge was Grindr, a geosocial and networking dating app released in 2009 (Kincaid, 2009), which is available on Android and iOS and can be downloaded from the app store. Tinder was released in 2011, and less than three years later (2014), the platform had registered over one billion users (Rao, 2011). Since then, a proliferation of dating apps have flooded the market (Hinge, Scruff, Happn, Coffee meets Bagel, Bumble etc.), tailored to different segments of the community. As Albury et al. (2019) indicate, dating apps are now 'mainstream'. Today, the notion of love, relationships, hook-ups and dating are deeply entangled with dating apps.

Dating app academic literature focuses largely on health (Albury et al., 2020), sexting (Huang et al., 2016), the exponential growth of a hook-up culture (Albury et al., 2017), dating app infrastructure (Duguay, 2019), and, to a lesser degree, the reinforcement or subversion of heteronormativity via dating apps (Saraiva et al., 2020). However, currently, there is little analysis of the deep continuities in love and intimacy which dating apps produce and facilitate. While dating apps present as a rupture in the way relationships are instigated and developed-that is, a movement from a physical environment to a digital landscape-they also present a continuity in pre-existing relationship dynamics and romantic masterplots. As this research demonstrates, despite the 'hook-up' dynamic generated by app architecture like Tinder, users continue to seek to emplot themselves in a romantic narrative.

\section{The Romance Masterplot}

\section{According to Peter Brooks (1996, p. 19):}

Our very definition as human beings is very much bound up with the stories we tell about our own lives and the world in which we live. We cannot, in our dreams, our daydreams, our ambitious fantasies, avoid the imaginative imposition of form on life. Life is in many respects narrativized in series and bunches of intersecting stories - never complete until our death, of course, but nonetheless oriented toward the significant chapterization of our existence.

To put this another way: storytelling is fundamental to the human experience. In particular, it is fundamental to how humans experience time. Paul Ricoeur (1990, p. 3 ), in his seminal work on time and narrative, argues that, '[t]ime becomes human time to the extent that it is organized after the manner of a narrative; narrative, in 
turn is meaningful to the extent that it portrays the features of temporal existence'. H Porter Abbott (2008, p. 3) uses the phrase 'narrative time' rather than Ricoeur's 'human time', and juxtaposes it with 'clock time'. The latter is measured in seconds, minutes, hours, while the former is measured in events-that is, the fundamental building blocks of narratives.

As David Shumway (2003, p. 14) notes, 'the name romance means, in addition to a kind of love, a kind of story' (emphasis in original). The romance masterplot contains many events by which people, to use Brooks' term, chapterize their lives. People regularly emplot themselves-or, as can be seen in this article, seek to emplot themselves-in the romance narrative by triggering this cycle of events through meeting a potential partner, thus attempting to position themselves as a romantic protagonist: as Catherine Belsey (1994, p. ix) notes, 'to be in love is to be the protagonist of a story'. If they are unsuccessful, and need to start the cycle again, there is often a specifically temporal anxiety which accompanies this: that is, the notion that they are running out of time, and that they will ultimately end up (importantly, 'end up' is a narrative term) single and alone, a state which exists in contrast with the romance plot's happy ending. As one participant (30 years of age, female, heterosexual, living in Sydney) indicated, 'Sometimes I feel like my life hasn't started yet ... like if I landed the right job, or the right guy, then things would move into gear'. We see this temporal anxiety in full force here: without an instigating narrative incident (often, as here, a romantic one), one is waiting for the story of one's life to begin rather than living it.

The constituent events of the romance plot have not necessarily remained stable over time or across cultures. In the West, while we can trace this plot back to the comedies of Ancient Greece, which end with union and usually marriage (Regis, 2003), romance plots have not always ended happily. In medieval romance, for instance, romantic love was often seen as a destructive force and was regularly positioned as adulterous: think, for instance, of the deleterious effect that the love of Lancelot and Guinevere has in medieval Arthurian romances. However, when companionate marriage emerged as a cultural ideal in the West in the eighteenth century, romantic love became reimagined as constructive, becoming the building block of the domestic unit and thus the nation-state (McAlister, 2020, p. 18). Romance plots with happy endings began to proliferate in popular literature-through, for example, the sentimental novel-and the romance plot as we know it now began to emerge. Contemporary popular culture is now saturated with the romance plot. This includes dedicated romantic genres, such as the popular romance novel, the filmic romantic comedy, and the love song, but romance plots also appear as sub- (or even central) plots in almost all other genres and media.

The romance plot of most dedicated romantic media involves a significant amount of conflict. In her explication of the popular romance novel, for instance, Pamela Regis (2003, p. 30) notes that two of the romance novel's eight elements are the barrier between the protagonists and the point of ritual death (ie. the moment where it seems like they can never be together). The broader cultural romantic masterplot involves less conflict between the potential couple, although working through conflict as a couple has increasingly become part of the narrative of marriage (Shumway, 2003). However, the masterplot shares 
the fundamental assumption with romantic media that 'there is a right man or woman for each person' and 'projects a life story that involves meeting that individual and living with him or her in marriage' (Shumway, 2003, p. 20).

In short, the constituent events of the romance masterplot can be expressed in the form we gave in the introduction: two people meet, have sex, fall in love, marry, have children, and live happily ever after. (This is generally considered to be a fairly heteronormative plot; however, we have seen it mapped onto queer couples increasingly more in recent years, not least via inscribing queer leads into generally heteronormative forms of popular culture, such as the Hallmarkstyle Christmas rom-com.) Not all of these milestones must necessarily occur-a couple might not choose to marry or have children, for instance-but these are still generally considered exceptions rather than the rule. These constituent events are often framed in specifically temporal terms: for instance, a couple that has a child and then later marries might refer to having done things 'out of order', where 'order' refers to the chronology above. The chronological position of sex in the masterplot has become increasingly mobile since the twentieth century saw the view that sex should only happen within marriage become dramatically less prevalent. Broadly speaking, it was replaced by a view that romantic love should be a necessarily precondition for sex (especially for women); however, this is also becoming increasingly more complex (McAlister, 2020).

These temporal concerns regularly provoke anxiety. Angus McLaren (1999, p. 220) argues that " $\mathrm{t}]$ here emerged in the twentieth century a "right time"... to reach sexual maturity, to lose one's virginity, to marry, to have children'. Because of its recent chronological mobility within the romance plot, among other things, sex is often the locus of a lot of anxiety about the 'right time'. This is evident in a significant amount of the conversation around dating apps, especially when the baseline assumption is that people are using them to hook up. These concerns are usually framed as moral, but they are also temporal and narrative: if sex occurs immediately after the meeting of two potential partners (ie. too early to be the 'right time'), then, this line of thinking goes, how can a romance plot ensue?

However, these are not the only temporal anxieties provoked by the romance masterplot. As one participant indicated in relation to meeting a significant other (33 years of age, female, heterosexual, living in Sydney), 'Certainly I get the sense that the clock is ticking... I hate that phrase, but yeah, I think it.' As can be seen in the findings section of this article, people often feel a distinct anxiety that they have missed their opportunity, their 'right time', for a committed and lasting romantic relationship. We can relate this back to cultural understandings of romance and the masterplot and the promise of security and happiness it brings. The jagged love cycle, theorised below, is a direct result of this temporal and narrative anxiety, as people repeatedly attempt to trigger the narrative cycle of events of the romance masterplot (wherein the first step is meeting someone), and despair of ever managing to successfully emplot themselves in it. 


\section{Jagged Love}

We theorise 'jagged love' informed strongly by Zygmunt Bauman's (2003) concept of 'liquid love'. Bauman contends that the twin forces of individualisation and social change which shaped modernity 'liquified' the solidity and security provided by romantic partnerships and family structures. A tension between security and freedom is exacerbated by these forces and creates a frailty in human bonds, with the result that enduring relationships are significantly less common. Instead, bonds formed under these new conditions are tied loosely, prepared from the onset for an easy unravelment. Bauman specifically identifies 'computer dating' as symptomatic of this 'liquid love', a place where love and enduring relationship bonds are reconfigured as entertainment, where users can date 'secure in the knowledge they can always return to the marketplace for another bout of shopping' $(2003,65)$.

Bauman's contentions are arguably somewhat hyperbolic. As Shaun Best (2019, p. 1096) notes in his critique of Bauman, modernity has not 'ushered in a sexual free for all rooted in individualism' nor have all relationships become more fluid-indeed, as Best mentions, the movement for the legalisation of same-sex marriage in the 2010s represents a demand for more solidity rather than fluidity. Similarly, a 2016 Australian study into dating apps found 'that traditional views on dating, relationships and monogamy are still largely prevalent' (Hobbs et al., 2016, p. 276), and that 'dating apps and internet dating more broadly are not "liquefying" ideals like romantic love, monogamy or a commitment to longer-term relationship' (Hobbs et al., 2016, p. 281). To put this another way: there is still widespread commitment to the ideals and milestones of the romantic masterplot.

However, there is no denying that the conditions of modernity have greatly shaped the way people approach romance. Eva Illouz (1997) argues that the twentieth century saw the emergence of romance being experienced through rituals of consumption, such as dates. Bauman (2003, loc. 1222) contends that the search for a partner itself has become a ritual of consumption, especially in an online space-what he describes as 'shopping for partners on the internet'. The widespread commitment to the romantic masterplot supports Illouz's (1997, pp. 2-3) argument that a person's beloved-or, in popular parlance, 'the one'-is constructed as 'unique and irreplaceable'. This is also where Bauman's conception of liquid love becomes useful. If someone searching for love is searching for 'the one' through the 'shopping' mechanism he describes, it is not surprising that bonds formed under these conditions would be deliberately tied loosely, so that they might be escaped quickly should 'the one' come along: to ensure, for example, that Mr Right Now can be easily discarded should Mr Right emerge. Thus is born a distinctly modern emotional state, which Bauman (2003, loc. 48) articulates through the image of people:

yearning for the security of togetherness and for a helping hand to count on in a moment of trouble, and so desperate to "relate"; yet wary of the state of "being related" and particularly of being related "for good", not to mention forever - since they fear that such a state may bring burdens and cause strains they neither feel able nor are willing to bear, and so may severely limit the freedom they need - yes, your guess is right - to relate... 
This is the result of the mismatch in logics between romantic love and capitalism that Illouz (1997) notes in Consuming the Romantic Utopia. The romantic partner, unlike the trading partner, is not interchangeable. As well established by the romance masterplot, having such a partner is extremely desirable: but the fear of accidentally committing to the wrong one (or the wrong 'one') is also real.

Bauman (2003, loc. 1222) is perhaps a little too cynical when he contends that when people 'shop' for a partner they do so secure in the knowledge that there is a 'a "no obligation to buy" promise and a "return to the shop if dissatisfied" guarantee'. While it is abundantly clear that not all users are using dating apps with the desire to find their one true love, there is ample evidence-both in this study and others, such as that undertaken by Hobbs et al. (2016)-that many people sincerely want to find a secure and lasting relationship, and inscribe themselves into the romance masterplot. This is mirrored in the core promise of the dating app Hinge: 'designed to be deleted'.

It is worth noting that this is not universally true across all users or all apps, and there is also significant evidence to suggest that app use is cyclical-liquid, in Bauman's terms-as users return to them again and again, often in a state of dissatisfaction. Tinder CEO Elie Seidman (Patel \& Carman, 2020) terms this 'episodic behaviour', and goes as far as describing a typical user's lifelong episodic journey with the app: '[i]f that starts at eighteen, it's a journey, and they spend their time on that journey'. The implication here is that the user's longest relationship is with the app, not a partner. However, while an app like Tinder might be designed to foster episodic behaviour, it is also true that many people read against the grain, so to speak, and use it and apps like it in a search for a partner. This episodic behaviour may be just as rooted in frustrated desire for a long-lasting romantic relationship as it is in a more regularly fulfilled desire for casual sex. As one participant reflected in relation to Grindr (32 years of age, male, MSM, living in Sydney), 'A lot of people think Grindr is a hook-up app, but I have many mates who have met their long term partners there too.'

The global pandemic seems to have two key effects on dating app users. The first, and most obvious, was that it precluded almost all possibilities for casual sex. The second was that it cast people into a state of ontological uncertainty. The pandemic, and its accompanying promise of lockdown, sent many people searching frantically for the security offered by the romantic masterplot, including many who had not hitherto used dating apps in this way. App use spiked near the beginning of the quarantine period in March as people sought to 'lock down an iso-partner' (female, 30 years of age, living in Sydney city). A participant (female, 30 years of age, living in Sydney city) indicated:

Just ... it was like my phone was constantly pinging throughout the day, like with people. So it alerts you when this person or that person has liked you... and it was just interesting because like it did that solid for like a week and a half ... so I think it was like initially people were thinking, oh shit, I need to line someone up for isolation.

However, this desire for security was quickly followed by a period of ambivalence and/or disillusionment, before the desire to look for love re-emerged again. As 
in the time before the pandemic, dating use was characterised by episodic behaviour, but there was little liquidity or flow to the way in which people approached relationships. Instead, what emerged was the paradigm we have termed 'jagged love', as participants see-sawed rapidly and violently between desperately wanting a romantic partner to navigate this difficult period with, and being disenchanted with the difficulty of dating during a pandemic and their own potential (or lack thereof) as a romantic protagonist.

\section{Method}

Data collection occurred across March / April 2020 and consisted of two iterative focus groups, and twenty one-hour in-depth interviews. Eight participants were also required to journal their experience of using dating apps across the month of March using the digital journaling tool Diarium. The sample was aged 18-35 years of age (reflecting the heaviest users of dating apps in Australia) living in NSW, and must have used or were currently using Bumble and Tinder (or both) dating apps. An invitation to participate in the research was issued at the end of a series of articles [researcher name, redacted for blind review] (2020a, 2020b) wrote for digital publication 10 Daily and Fairfax national publications.

This research topic lent itself towards conducting iterative focus groups, to gather shared understandings of dating apps but also to shake out any new and different ideas or ways of thinking around dating apps. The focus groups were conducted in Sydney city, and regional participants were provided the option of connecting via Zoom. Participants were asked set questions in the first focus group around their dating app experience, usage practices, personal presentation on app, expectations, and desires. Questions were tailored for the second focus group around trends that emerged, and participants were also asked to design their ideal dating app architecture and functionalities in groups. In-depth interviews were conducted over Zoom, and were approximately an hour in length, following a semi-structured format. Eight participants also journaled their experience during the month of March and were asked to do so for at least one hour per week, capturing screen grabs of their experience if they desired.

\section{Sample and Limitations}

As indicated, twenty participants were recruited: twelve were heterosexual women, six were heterosexual men and two were queer men. Two participants were consensually-non-monogamous, the rest were 'single' or were in the preliminary stages of dating ('talking to') someone. The research intended on capturing heterosexual dating app practices, although it did not seek to exclude other sexualities or ways of being.

It should be noted that there is a clear heteronormativity in the romance masterplot and its milestones, including its impetus towards the couple norm (Roseneil et al., 2020). The effect of this has been grappled with at length in queer theory, in 
particular through Tom Boellstorff's (2007, p. 228) theorisation of 'straight time': 'an emically salient, socially efficacious, and experientially real cultural construction of temporality across a wide range of political and social positions... shaped by linked discourses of heteronormativity, capitalism, modernity, and apocalypse'. Questions of straight time were particularly interrogated during the debates over the legalisation of same-sex marriage, because-very broadly speaking-marriage is a clear marker in a narrative governed by straight time. As Boellstorff (2007) notes, there was significant tension between the desire of equal rights (ie. the right to marry) and the desire to resist the imposition of a heteropatriarchal temporal narrative. There are not enough LGBTQ + participants in our sample for us to make any substantive claims about how app users belonging to these communities interact with the romance masterplot and how any resistance to 'straight time' might complicate this. The results in this paper should be read as speaking predominantly to heterosexual dating practices, with further targeted inquiry to capture practices in queer app-based dating.

Four participants lived in regional NSW, while the majority were from Sydney city hubs like Parramatta or Sydney CBD. It was important to select participants from regional and metro areas, as location creates diverse dating app experiences: for example, those living in regional areas do not have the same dating app profile anonymity as those in larger cities. Five of the participants were born overseas, and two others were first generation Australians with Culturally and Linguistically Diverse backgrounds.

Participants ranged in age from 18 to 35 . This makes them, broadly speaking, digital natives, with higher familiarity and comfort levels with app-based dating than older demographics. The results should also be interpreted with this limitation in mind: results might be markedly different with different demographic, and further dedicated inquiry is needed to explore this.

\section{Time Period}

Data collection occurred during a curious period. This research was scheduled to occur in March and April 2020. However, this coincided with the COVID-19 lockdown period for NSW. The final focus group was conducted prior to the full lockdown directive, and the COVID-love narrative coloured the discussion. In-depth interviews were scheduled to be conducted via Zoom, and this continued during lockdown, as did the e-journalling. The experiences captured and documented highlight an intensely unique period of time and of dating culture.

\section{Findings and Analysis}

David Shumway (2003, p. 2) argues that we gain a lot of life lessons about romance from fictional representations of it. Importantly, this encompasses not just what romantic love is or what it feels like, but the constituent events that make up a romantic narrative. When people look for romantic love, they are often seeking 
out ideas that they have imbibed from representations of love, or seeking to try and kickstart a romance narrative in which they can emplot themselves.

This is clearly evident in the interview data. For instance, all participants were quite philosophical and/or sad about never having met 'the one' or an equivalent to 'the one'-that is, the person with whom they can undertake those constituent events of the romance narrative, the right person with whom they can achieve a happily ever after. This search for 'the one' sends them to dating apps. As one participant (29 years old, female, heterosexual, living in Sydney) said:

I'm turning 30 this year, and it's kind of that age when you start thinking, what does the next decade look like. All of my friends are now either engaged or married, some of them are onto their first kid, there is definitely more pressure from that perspective to take up dating apps more so.

There is a clear temporal anxiety embedded here: a sense that she either has or is beginning to fall behind, that the 'right time', as McLaren (1999) might put it, might be passing her by. Therefore, she needs to begin her romance plot soon, lest she be left behind altogether, and the apps provide the easiest avenue for doing so.

Participants-especially women-often recuperated their desire to find the one, following up their disappointment that they had not yet found them with a statement about how they might not even need someone. As expressed by the same participant (29 years old, female, heterosexual, living in Sydney):

So there's a part of me that's like "am I ever going to meet someone if I'm not on these apps where everyone is at", and the other half of me is like "I' $m$ just going to go about my normal and regular life and if someone comes into my path then great".

Encoded in this is an ambivalence not just about the possibility of romantic love, but also about the apps themselves. While dating apps are an obvious venue for meeting people, using an app also means that the participant is actively seeking love. It becomes artful, rather than artless, in a way that runs counter to many people's understanding of the romance masterplot. This was a key point that many participants raised: they felt that love and relationships should form in 'organic' ways, and that dating apps were the opposite-rigidly pre-meditated. ${ }^{1}$

In particular, the meet-cute was invoked in this respect by several participants. This is a trope rooted particularly in filmic romantic comedies, where 'the prospective lovers encounter each other and sparks fly' (Grindon, 2011, p. 9). It is neatly meta-textually explained in 2006 romantic comedy The Holiday, where Arthur (Eli Wallach) explains to Iris (Kate Winslet):

It's how two characters meet in a movie. Say a man and a woman both need something to sleep in, and they both go to the same men's pajama department.

\footnotetext{
1 This desire for romance to be 'organic' led some participants to seek potential romantic matches through other platforms, such as Instagram and Tik-Tok, by 'sliding into their DMs 'female, heterosexual, 29 years old, Sydney-city). This was perceived as less pre-meditated, as the intent of these platforms is not dating.
} 
And the man says to the salesman, "I just need bottoms". The woman says, "I just need a top". They look at each other, and that's the meet-cute. ${ }^{2}$

Importantly, the meet-cute is always accidental. Dating apps, therefore, which rely on a logic of active choice and not on happenstance, are not at all conducive to this kind of rom-com moment: as Thomas Doherty (2010, p. 26) writes, 'hooking up via match.com is not a meet cute' (emphasis in original). This leaves people seeking romance caught between two opposing forces. The apps provide their best opportunity to meet someone (potentially even 'the one'), but they also close down the possibility of the kind of romance they may have envisioned for themselves (usually envisioned in specifically narrative terms). In some instances, this led to a kind of roll-on effect in terms of self-confidence, where those participants felt like they were not special enough for a kind of highly narrativized romantic comedy moment like a meet-cute, and that the apps were their only option if they were to ever find a partner. There was a strong desire for romance to be 'organic', but also a strong sense that they were not the kind of person who could find romance without using the apps to explicitly seek it out. As one participant (21 years old, female, heterosexual living in Sydney) said, 'I'd love to meet someone on the bus, or in a café ... and have one of those Hollywood moments, but I'm just not that type of person. I'm a bit awkward'; and as another (30 years old, male, heterosexual, living in Sydney) put it, 'Like, where am I going to meet someone? In the aisle at Woolies?'. 3

The opportunities for any kind of organic rom-com meet-cute were made even smaller by the pandemic. The pandemic had a clear impact on dating app usage, with participants describing a sharp increase in matches and conversations at the beginning of the lockdown (March 2020). This included new users-as one participant (27 years old, male, heterosexual, living in Parramatta) said, 'This weird thing happened, where all of these new faces started popping up. Like before I was seeing repeats, the same people going around, but there was like ... this influx of people'. We can theorise several interconnected reasons for this. For example, the uncertainty the pandemic engendered presumably led many people, including people who had not used the apps before, to seek the security promised by the romantic masterplot. Similarly, the apps also became not just the easiest, but one of the only venues in which to meet people, as access to physical spaces closed down. ${ }^{4}$ Finally, a lockdown situation actually plays into some established romantic tropes, thus providing potential new opportunities for people to script a romance narrative.

The 'forced proximity' trope, for instance, revolves around two characters having to share a confined space for an extended period of time, inevitably resulting in

\footnotetext{
2 The scene described here is a reference to the 1938 screwball comedy Bluebeard's Eighth Wife. The screenplay was co-written by Billy Wilder, who allegedly kept a notebook of meet-cute ideas (McDonald 2007, p. 12).

3 Woolies refers to Woolworths, a major Australian supermarket chain.

4 Interestingly, no participants reported flouting lockdown rules to meet up in person, despite the appeal of the familiar trope of "forbidden" love. There are a number of possible reasons for this, including 1) they might not have wanted to report this kind of rule-breaking to a researcher, and 2) compared to other territories, Australia had a relatively high overall level of compliance with lockdown rules, suggesting something about national character (Liddy \& Tilley 2020; Murphy et al., 2020).
} 
them falling in love: as Jessica Avery (2018) describes it, it is 'an umbrella term for any plot point that forces the two main characters to spend time together (whether they want to or not)'. This trope often manifests in texts where people are snowed in together, stranded on a desert island, locked together in a safe house, or find themselves sharing a room for a night in which there is only one bed. The prospect of an extended lockdown, while frightening, clearly engenders this kind of possibility. This is mirrored in romance narratives produced about the pandemic. While, at the time of writing in late 2020, most popular culture had not yet caught up with the pandemic, one area in which its affordances had begun to be explored was selfpublished romance fiction. ${ }^{5}$ The majority of novels published which engage explicitly with the pandemic employ the forced proximity trope. Author Jamie Knight has been the most prolific in the field, publishing twenty (as of the time of writing) books in 2020 in her Love Under Lockdown series, almost all of which utilise this trope. For example, part of the blurb for the twentieth book, Cramped Quarters: An Enemies to Lovers Accidental Roommates Romance (2020) reads:

And I'm glad the pandemic means we have to socially distance.

That way I have to stay at least six feet from his chiseled chest.

But then the school changes our living arrangements.

And assigns him to live in my small dorm during quarantine!

It's no longer possible to keep my eyes off his ripped abs.

And he says he can't keep his hands off my curvy hips.

We were stuck together, but maybe we're headed for happiness.

As long as our family and friends don't find out!

Material like this has an obvious level of melodrama. However, the spike in app usage in March-described by one participant (30 years old, female, heterosexual, living in Sydney) as 'Initially there was this frenzy ... like oh shit, I have to lock down an iso-partner'-can be read as at least partially in dialogue with a desire to embody a potential forced proximity romance narrative. The pandemic placed participants in a state of ontological uncertainty by disrupting the everydayness of modernity. The romance plot offers a sense of security, and the heightened circumstances of lockdown offer apparent opportunities for people to emplot themselves in equally heightened narrative arcs like the one presented by the forced proximity trope.

This is the beginning of what we term the jagged love cycle, where the majority of participants became trapped in a cyclical loop. This involved downloading dating apps (sometimes multiple apps), vigorously swiping, matching, starting multiple chats (with low level personal investment), becoming quickly bored or exhausted with the process and their matches, deleting the dating apps, and then after approximately two weeks of experiencing FOMO (Fear of Missing Out) and loneliness, redownloading the apps. The cycle would then begin again and occurred on repeat

\footnotetext{
5 While the process for traditional publishing is quite lengthy (an eighteen-month turnaround would be relatively quick), self-publishing lacks the levels of gatekeeping, and thus can respond to events far more quickly.
} 
for several months during the lockdown period. Many participants recognised this cycle to some degree, particularly the 'down time' and would talk about being 'on a break from dating apps' (21 years of age, heterosexual, female, living in Sydney). However, they found it hard to pinpoint the reason for the loop, or the loop itself. The cycle itself, and the emotions experienced, were heightened-high-highs and low-lows were described almost side-by-side. Participants detailed swings from extreme elation at having experienced a dating app connection, to utter ambivalence, and deletion of dating apps. There was nothing fluid about the shifts, the experiences reported seemed elevated and intense. One participant indicated, (30 years old, female, heterosexual, living in Sydney), 'I've never cried this much before.'

There were several key factors which led participants from the high end of the jagged love cycle, as discussed above, to the low end, where they became disenchanted with the apps. One was the low level of investment in potential matches, which led to participants feeling bored and exhausted by their in-app interactions. Berlant (1998, pp. 282-83) argues that intimacy 'involves an aspiration for a narrative about something shared, a story about both oneself and others that will turn out in a particular way'. This idea of 'sharing' is echoed by various scholars in relation to intimacy. McGlotten (2013, p. 1) indicates intimacy involves sharing something that is 'inward to our personhood'. Giddens $(1991,1992)$ describes the need for mutual self-disclosure, with which Jamieson (1998, p. 1) concurs, contending that intimacy is characterised by 'constantly revealing your inner thoughts and feelings to each other'. As participants sought to keep their 'numbers high'-often a strategy to ensure that at least one of the matches would 'come off', or a ploy to guard against 'obsessing over someone'-this mutual self-disclosure and sharing of intimate details required to form an intimacy did not occur. Instead participants were stuck in what they described as 'boring' and often 'exhausting' and repetitive chats which involved colourless discussions and topline details about their lives. One participant (female, heterosexual, 30 years old, living in Sydney) indicated:

I also hate the mundane chat, and I lose interest going through that phase of that small stuff. And it's fine when you're on a first date and you're face to face, because you can pick up on a vibe from them and have a joke ... it's just really artificial online. It's like the middle level has been removed, and then the two levels on either side are still there. It's like that game with the shuffle board, like you're throwing it to them and they're throwing it back.

We see here that the dating app paradigm not only removes some the key milestones and signposts of the romance narrative (the in-person first date, for instance), but also the accompanying emotional context. One of the core narrative promises of romance is excitement (think, for instance, of the blurb of the quarantine romance quoted above), but what participants are experiencing here is the opposite: boredom. This mundane, low investment chat was a key factor for the deletion of dating apps. Participants lost faith that the dating app paradigm could provide them with the entry point to the romantic masterplot, and they found it very difficult to reach the level of communication required to build any kind of intimacy in the digital space of the app.

Participants also expressed the notion that once they returned to physical settings, love would once again have an opportunity to run its natural and 'organic' 
course. For instance, this participant (30 years old, living in Sydney, female, heterosexual) stated:

I probably feel more hopeful about the end of isolation. I think that the nature of online dating might slightly change, because people will be wanting to have more human contact, they'll want to be going out more and connecting ... for me I'm thinking to that phase, and I'm happy to go through this stage now.

This idea that solely digital encounters were not sufficient to determine whether or not someone was a potential partner and that physical interaction was fundamental manifested in several ways. First, participants became disenchanted with the lack of investment evident in DM conversation over multiple matches. But secondly, they were also reticent to 'over-invest' in one person, given they might not be able to meet this person face-to-face for an extended (and unknown) time period. Participants were concerned that they might 'over-invest' in a match and then discover that they had 'no chemistry' in a real-world environment. Participants often described an 'animated' quality which was lost on dating apps, a three-dimensional component which could not quite be transmitted in the digital landscape, constituting part of the potential 'chemistry'. For example, according to this participant (27 years of age, male, heterosexual, living in Parramatta):

There's so much lost in the digital domain. It's kind of harsh, because there are key things about you that just don't come across. Like, are you polite to people? Do you have good posture? Are you a smiley person? Are you loud? Are you quiet? What if I meet them face to face and the chemistry is just not there?

There was often judgment directed towards those who had been in immersed in fully 'digital' romances, which lacked face-to-face components. A certain derision was cast towards these 'faux' types of relationships, such as by this participant (35 years of age, heterosexual, female, living in regional NSW):

I've got a girlfriend at the moment who is six months into an online romance or telephone romance or video romance or whatever that is, but they haven't met yet. But unless you put it into the real world you just never, never know. You just don't. It can be this kind of Jane-Austen-esque life and romance, but if you don't have that chemistry, and that smell and that attraction in real life, it's just not going to translate.

Chemistry, here, is something ineffable which can only be ascertained in the physical realm. Catherine Belsey (1994, p. 23) argues that the promise of 'true love as the romances portray' is 'to bring mind and body back into perfect unity', uniting '[p]hysical sensation, the overwhelming intensity of erotic desire' with 'rational and moral commitment, a shared life of sympathy and support'. We could roughly equate these with 'chemistry' and 'intimacy'. Participants were frustrated at not being able to develop the latter in the app space, but do seem to have maintained a belief that it was possible, albeit a fluctuating belief depending on where they were 
in the jagged love cycle. The former, however, was positioned as impossible without a physical encounter. The pandemic provided no opportunities for these physical meetings to occur. This thus became one of the reasons-alongside the failure of the development of intimacy-that participants became bored and exhausted with the dating app process and the behaviours that app architecture engenders, such as multiple matches and low level investment. For example, according to one participants (30 years of age, male, heterosexual, living in Sydney):

I actually don't know where any of this can go ... I'm chatting to all of these people, but I can't physically meet them, so maybe I'm just talking to them out of boredom. Like it's a little ping of excitement.

This represented the other end of the jagged love cycle, the initial excitement about the potential of finding an iso-partner followed by a despair about the possibility of romance being possible in such an environment. However, participants soon cycled back. The majority spent a couple of weeks off app before re-downloading, expressing a sense of FOMO or loneliness as a key driver for this. We use the specific term FOMO here, as participants defined a clear fear of missing out, an idea that 'everyone is on the apps' and that if they weren't participating in this paradigm they had essentially 'committed relationship suicide'.

Cyclical use of dating apps is not a new phenomenon. The drift of users on and off apps is often driven as much by dissatisfaction as it is by users finding a secure and lasting romantic relationship. However, in the heightened circumstances of the pandemic, the fluidity of this process-its liquid nature, to use Bauman's (2003) terms-disappeared. There was nothing fluid about going from maniacally swiping and chatting, deleting, to returning to the apps. Participants were clearly rattled by the jagged cycle, expressing in a consistent sense that they were personally 'broken' or there was 'something wrong with [them]' (heterosexual, female, 30 years old, living in Sydney). The pandemic saw a desperation from participants to emplot themselves in the romance masterplot, to attain the security that provides, to not miss their 'right' moment for love, and an excitement about the unique affordances of the lockdown for a particular kind of romantic narrative. However, it also saw despair about the difficulties of proceeding beyond small talk to more intimate levels of conversation, and the inability to determine romantic chemistry without physically meeting. Trapped in the jagged love cycle, participants found themselves both strongly desiring romance, but unable to reach the apotheosis of the romantic masterplot.

\section{Conclusion}

This is a small study, but it clearly demonstrates the ways in which the romantic masterplot affects how people approach romance on dating apps. ${ }^{6}$ Participants express their desire to meet 'the one' and for 'organic' relationships, developing

\footnotetext{
${ }^{6}$ As noted above, the sample for this study skews heavily towards heterosexual people, and more research is needed to understand how this plays out in queer app-based dating.
} 
in line with dominant cultural narratives of romance. They must negotiate the fact that apps offer the best chance to meet someone, but are also an environment characterized by logics of premeditation and strategy, which runs counter to the artlessness inherent in most romance narratives. App use is therefore often cyclical, as people fall in and out of relationships with each other and the apps themselves.

This was intensified by the global COVID-19 pandemic. While previously there was a liquidity in dating app use, the pandemic engendered what we have called the jagged love cycle, as participants ricocheted violently between the desire to find someone and disenchantment with the process of searching. Participants wanted the security of finding a partner, to mitigate both potential loneliness during lockdown and to assuage the temporal anxiety associated with the romance narrative (that is, not to miss the 'right' time to find love, especially in an environment as heightened as the pandemic). There was also a certain element of excitement at the kinds of romance narratives a lockdown situation could engender, such as those characterized by a forced proximity trope. But this was mirrored by frustration and disappointment. In addition to the pre-existing tension between seeking romance on-app and the desire for an 'organic' relationship, participants were frustrated by the lack of development of intimacy in their multiple low-level matches, and by the inability to determine chemistry without physically meeting. The jagged love cycle is characterized by a battle between an ontological sense of security and insecurity, a desire to tie bonds, but keep them loose at the same time-liquid love, only on steroids.

Author contributions Two authors contributed 50/50. The data set was developed by the first author.

\section{Declarations}

Conflict of interest The author(s) declare that they have no conflict of interest.

Consent to participate All participants consented to participate as per the ethics approval.

Consent to publish All participants consented to publish as per the ethics approval (publish de-identified).

Data availability Data not currently available.

Ethical approval Project number: H13616 approved by Western Sydney University.

\section{References}

Abbott, H. P. (2008). The Cambridge introduction to narrative. Cambridge University Press.

AFP. (2019, June 8). Dating apps and STDs: a million new sexually transmitted infections a day, WHO warns. https://www.scmp.com/lifestyle/health-wellness/article/3013588/dating-apps-and-stds-milli on-new-sexually-transmitted. 
Albury, K., Burgess, J., Light, B., Race, K., \& Wilken, R. (2017). Data cultures of mobile dating and hook-up apps: emerging issues for critical social science research. Big Data \& Society, 4 (2), published first online, doi:https://doi.org/10.1177/2053951717720950.

Albury, K., et al. (2019). Safety, risk and wellbeing on dating apps: final report. Output from the Australian Research Council Linkage Project 'Safety, Risk and Wellbeing on Digital Dating Apps,' published first online, doi:https://doi.org/10.25916/5dd324c1b33bb.

Albury, K., McCosker, A., Pym, T., \& Byron, P. (2020). Dating apps as public health 'problems': Cautionary tales and vernacular pedagogies in new media. Health Sociology Review, 29(3), 232-248. https://doi.org/10.1080/14461242.2020.1777885

Avery, J. (2018, December 27). A beginner's guide to forced proximity romance novels. Book Riot. https://bookriot.com/forced-proximity-romance-novels/.

Bailey, J. (2012, February 12). Changing the game. The Age. https://www.theage.com.au/lifestyle/chang ing-the-game-20120211-1sy90.html\#ixzz1mTfkGD2D.

Bauman, Z. (2003). Liquid love: on the frailty of human bonds. Polity.

Belsey, C. (1994). Desire: Love stories in Western Culture. Blackwell.

Berlant, L. (1998). Intimacy: A special issue. Critical Inquiry, 24(2), 281-288. https://doi.org/10.1086/ 448875

Best, S. (2019). Liquid love: Zygmunt Bauman's thesis on sex revisited. Sexualities, 22(7-8), 1094-1109. https://doi.org/10.1177/1363460718795082

Boellstorff, T. (2007). When marriage falls. GLQ: A Journal of Lesbian \& Gay Studies, 13, 227-248. https://doi.org/10.1215/10642684-2006-032

Brainz. (2011). History of online dating. https://www.brainz.org/history-online-dating/.

Brooks, P. (1996). The law as narrative and rhetoric. In P. Brooks \& P. Gerwitz (Eds.), Law's stories: narrative and rhetoric in the law (pp. 14-23). Yale University Press.

Bruce-Smith, A. (2017, May 11). 15\% of the Australian population is now on Tinder. Pedestrian. https:// www.pedestrian.tv/news/15-of-the-australian-population-is-now-on-tinder/.

Doherty, T. (2010). The rom-com genre and the shopping gene. OAH Magazine of History, 24(2), 25-28. https://doi.org/10.1093/maghis/24.2.25

Duguay, S. (2019). You can't use this app for that: Exploring off-label use through an investigation of tinder. The Information Society, 36(1), 30-42. https://doi.org/10.1080/01972243.2019.1685036

Fetters, A. (2018, December 21). The five years that changed dating. The Atlantic. https://www.theatlantic.com/family/archive/2018/12/tinder-changed-dating/578698/.

Fetters, A., \& Tiffany, K. (2020, February 26). The 'Dating Market'is getting worse. The Atlantic. https://www.theatlantic.com/family/archive/2020/02/modern-dating-odds-economy-apps-tindermath/606982/.

Gebel, M. (2019, February 11). I'm 25, and I talked to 3 single women in their 50s about what it's like to use dating apps like Tinder and Bumble. Their experiences surprised me. Business Insider. https:// www.businessinsider.com.au/older-women-dating-apps-experiences-tinder-bumble-2019-2?r=US\& $\mathrm{IR}=\mathrm{T}$.

Giddens, A. (1991). Modernity and self-identity: Self and society in the late modern age. Polity.

Giddens, A. (1992). The transformation of intimacy: Love and eroticism in modern societies. Polity.

Grindon, L. (2011). The Hollywood romantic comedy: Conventions, history, controversies. Wiley.

Hobbs, M., Owen, S., \& Gerber, L. (2016). Liquid love? Dating apps, sex, relationships and the digital transformation of intimacy. Journal of Sociology, 53(2), 271-284. https://doi.org/10.1177/14407 83316662718

Huang, E.T., Williams, H., Hocking, J.S., \& Lim, M.S.C. (2016). Safe sex messages within dating and entertainment smartphone apps: a review. JMIR MHealth and UHealth, 4 (4). Available from: https://mhealth.jmir.org/2016/4/e124/. doi:https://doi.org/10.2196/mhealth.5760.

Illouz, E. (1997). Consuming the romantic utopia: Love and the cultural contradictions of capitalism. University of California Press.

Jamieson, L. (1998). Intimacy. Polity.

Kermode, F. (1979). The genesis of secrecy: On the interpretation of narrative. Harvard University Press.

Kincaid, J. (2009, March 25). Gay dating makes its way to the iPhone. TechCrunch. https://techcrunch. com/2009/03/25/gay-dating-makes-its-way-to-the-iphone/.

Knight, J. (2020). Cramped quarters: an enemies to lovers accidental roommates romance. Self-published. 
Liddy, M., \& Tilley, C. (2020, December 10). Four Australia Talks findings that can help us understand 2020. ABC. https://www.abc.net.au/news/2020-12-10/australia-talks-findings-2020-insights/12955 570 .

Macleod, C., \& McArthur, C. (2018). The construction of gender in dating apps: An interface analysis of tinder and bumble. Feminist Media Studies, 19(6), 822-840. https://doi.org/10.1080/14680777. 2018.1494618

McAlister, J. (2020). The consummate virgin: Female virginity loss and love in Anglophone popular literatures. Palgrave.

McDonald, T. J. (2007). Romantic comedy: Boy meets girl meets genre. Columbia University Press.

McGlotten, S. (2013). Virtual intimacies: Media, affect, and queer sociality. SUNY Press.

McLaren, A. (1999). Twentieth-century sexuality: A history. Blackwell.

Meyers, N. (Directer). (2006). The holiday. Columbia Pictures.

Murphy, K., et al. (2020, June 30). Coronavirus spike: why getting people to follow restrictions is harder the second time around. The Conversation. https://theconversation.com/coronavirus-spike-why-getti ng-people-to-follow-restrictions-is-harder-the-second-time-around-141287.

$\mathrm{Ng}$, A. (2019, January 23). Cyberstalkers are crowdsourcing danger to victims 'doorsteps with dating apps. CNet. https://www.cnet.com/news/cyberstalkers-are-crowdsourcing-danger-to-victims-doors teps-with-dating-apps/.

Patel, N. \& Carman, A. (2020, June 9). Tinder CEO Elie Seidman on finding love during the pandemic. The Verge. https://www.theverge.com/21284420/tinder-ceo-elie-seidman-interview-dating-pande mic.

Rao, L. (2011, March 31). Exclusive: IAC hatches Hatch Labs, a technology sandbox to incubate mobile startups. TechCrunch. https://techcrunch.com/2011/03/31/exclusive-iac-hatches-hatch-a-techn ology-sandbox-to-incubate-mobile-startups/.

Regis, P. (2003). A natural history of the romance novel. University of Pennsylvania Press.

Ricoeur, P. (1990). Time and narrative, vol. 1. (K. McLaughlin \& D. Pellauer, Trans.). Chicago University Press.

Roche, G., Maruyama, H., \& Kroik, А. V. (2018). Indigenous efflorescence: Beyond revitalisation in Sapmi and Ainu Mosir. ANU Press.

Roseneil, S., Crowhurst, I., Hellesund, T., Santos, A. C., \& Stoilova, M. (2020). The tenacity of the couple-norm: Intimate citizenship regimes in a changing Europe. UCL Press.

Saraiva, L. A. S., et al. (2020). Heteronormativity, masculinity and prejudice in mobile apps: The case of Grindr in a Brazilian city. Brazilian Business Review, 17(1), 114-131. https://doi.org/10.15728/bbr. 2020.17.1.6

Shumway, D. (2003). Modern love: Romance, intimacy, and the marriage crisis. NYU Press.

YouGov. (2017, November 23). A third of Aussies have used internet dating. https://au.yougov.com/news/ 2017/11/23/internet-dating/.

Publisher's Note Springer Nature remains neutral with regard to jurisdictional claims in published maps and institutional affiliations. 